\title{
Upper GI Endoscopy in Children: An Experience from Bangabandhu Sheikh Mujib Medical University (BSMMU)
}

\author{
MD. WAHIDUZZAMAN MAZUMDER ${ }^{1}$, MD. RUKUNUZZAMAN² ${ }^{2}$ ATIAR RAHMAN ${ }^{3}$, SM BAQUI BILLAH $^{4}$, \\ KANIZ SULTANA ${ }^{5}$, ASM BAZLUL KARIM ${ }^{6}$
}

\begin{abstract}
Background: Upper gastrointestinal (UGI) endoscopy is a safe and sensitive investigation in the diagnosis of upper gastrointestinal diseases. There is limited study on paediatric upper Gl endoscopy in our country. This study was done only in BSMMU, a tertiary care health facility of Bangladesh.

Objectives: The aim of the study was to find out the indications, common endoscopic findings and immediate post procedure complication of UGI endoscopy in children.

Methods: This is a retrospective analysis of 100 patients from August 2013 to October 2014. The indications for UGI endoscopy, common endoscopic findings and immediate post procedure complications were collected from case recording \&were analyzed.

Results: The commonest indication was upper GI bleeding in the form of hematemesis with or without melenae (41\%). The most common finding was esophageal varices (49\%). Less common findings were esophagitis, gastritis \& gastro-duodenal ulcer. There was no post procedure complication.

Conclusion: In the study, the commonest indication for Pediatric UGI endoscopy was upper $\mathrm{Gl}$ bleeding and the commonest endoscopic abnormality was esophageal varices. No immediate post procedure complication was noted in the study.
\end{abstract}

Key words: Upper Gl endoscopy, Paediatric age group.

\section{Introduction}

Gastrointestinal diseases are important health related problems worldwide, especially in pediatric age group. ${ }^{1}$ Upper gastrointestinal (UGI) endoscopy is the most sensitive investigation for diagnosing upper $\mathrm{Gl}$ disease. Bozzini is the pioneer of modern gastroenterology, who used candle-powered lichtleiter for the first time in 1805 in medical history. ${ }^{2}$ After the introduction of

1. Assistant Professor, Department of Pediatric Gastroenterology \& Nutrition, Bangabandhu Sheikh Mujib Medical University (BSMMU), Dhaka, Bangladesh.

2. Associate Professor, Department of Pediatric Gastroenterology \& Nutrition, Bangabandhu Sheikh Mujib Medical University (BSMMU), Dhaka, Bangladesh.

3. Assistant Professor, Department of Pediatric Gastroenterology \& Nutrition, Bangabandhu Sheikh Mujib Medical University (BSMMU), Dhaka, Bangladesh.

4. Senior consultant, Department of Pediatric Gastroenterology \& Nutrition, Bangabandhu Sheikh Mujib Medical University (BSMMU), Dhaka, Bangladesh.

5. Medical Officer, Dhaka Medical College.

6. Professor, Department of Pediatric Gastroenterology \& Nutrition, Bangabandhu Sheikh Mujib Medical University (BSMMU), Dhaka, Bangladesh.

Correspoondence: Dr. Md. Wahiduzzaman Mazumder, Assistant professor, Department of Pediatric Gastroenterology \& Nutrition, Bangabandhu Sheikh Mujib Medical University (BSMMU), Dhaka, Bangladesh, E-mail:mazumdermw@ gmail.com. flexible endoscopy by Hirschowitz in 1950's, use of upper $\mathrm{Gl}$ endoscopy has become a routine $\mathrm{GI}$ procedure. ${ }^{3}$ Later on, fiberoptic endoscopy for children developed in 1970's and upper GI endoscopy has now become a standard diagnostic procedure for many gastrointestinal problems in children. ${ }^{4-6}$ Diagnostic endoscopy is a safe procedure, with less than $2 \%$ minor complication rate. ${ }^{7}$ Despite the high diagnostic yield, upper GI endoscopy is still an under-utilized tool and information regarding its efficacy is scanty in most of the developing countries. ${ }^{8}$ This underutilization is mainly due to lack of awareness about the role of this important diagnostic modality in children which prevents referral of these children to a centre where this facility is available. On the other hand, factors like lack of trained Pediatric Gastroenterologists or lack of well-equipped Pediatric endoscopy suites in resource-limited countries may also play an important role in under utilization of this procedure. Furthermore, there is lack of data from developing countries regarding the appropriate indications of endoscopy in children. ${ }^{9}$ There is no available data in our country in this regard. Therefore, we carried out 
this hospital-based retrospective study to find out the common indications, endoscopic findings and complications of Pediatric upper $\mathrm{Gl}$ endoscopy in our setup, to raise awareness regarding use of upper $\mathrm{GI}$ endoscopy amongst paediatricians in diagnosing upper GI problems in our country.

\section{Materials and Methods}

The study was carried out at the Department of Pediatric Gastroenterology \& Nutrition, Bangabandhu Sheikh Mujib Medical University (BSMMU), Dhaka, Bangladesh. The medical records of all patients under the age of 15 years who underwent upper $\mathrm{Gl}$ endoscopy from August 2013 to October 2014 were reviewed retrospectively after permission from departmental ethical committee. All of the Paediatric patients on whom upper GI endoscopy was performed during the study period were included in the study. The need for endoscopy was decided by the paediatric gastroenterologist as well as by the general paediatricians. After careful explanation of the procedure details and potential complications to the patient/parents, informed written consent were taken. After proper preparation, upper $\mathrm{Gl}$ endoscopies were performed by the faculty members. Model of endoscopy machine used for this purpose was Olympus CV-150. Mode of anaesthesia was decided by performing faculty member depending upon patient's age, level of cooperation and physicians comfort level. Parenteral Midazolam was used as sedatives. Endoscopic findings were recorded for each patient. Patients were kept in observation room to see the immediate post procedure complications. Patient's demographic data like age, sex were recorded. For descriptive purpose patients were divided into three age groups. Indications for upper GI endoscopy \& findings were recorded for each patient. The frequencies of various indications and endoscopic findings were calculated, SPSS (statistical package for social science) Version 18.0 statistical program was used when needed.

\section{Results}

During the study period, a total of 100 patients underwent upper $\mathrm{Gl}$ endoscopy. Mean age of patients was 8.5 years with range from 2 months to 15 years. Older children (aged $>10$ years) had the highest frequency of upper $\mathrm{GI}$ endoscopy, i.e. $40 \%(n=40)$, followed by 5 - 10 year age group i.e. $38 \%(n=38)$. The frequency of endoscopy in children below 5 years of age was $22 \%$ (Table -1). There was no immediate post procedure complications in this study. GI bleeding in the form of hematemaesis and /or melenae was the most common (41\%) indication for the procedure. Follow-up endoscopy for suvillence of esophagial varices, was the next cause (33\%) of the procedure. In $12 \%$ patients upper $\mathrm{Gl}$ endoscopy was done due to pain abdomen (Figure-1). Abnormal endoscopic findings were found in $65 \%$ patients. Of the abnormal findings, the commonest (49\%) was esophagial varices. Gastroesophagitis was found in $10 \%$, gastroduodenal ulcer in $4 \%$, and endoscopic findings w ere normal in $36 \%$ of cases (Table-II).

Table--I

Age distribution of patients $(n=100)$

\begin{tabular}{lcc}
\hline Age & No. & Percentage $(\%)$ \\
\hline$<5$ years & 22 & 22 \\
$5-10$ years & 38 & 38 \\
$>10$ years & 40 & 40 \\
\hline
\end{tabular}

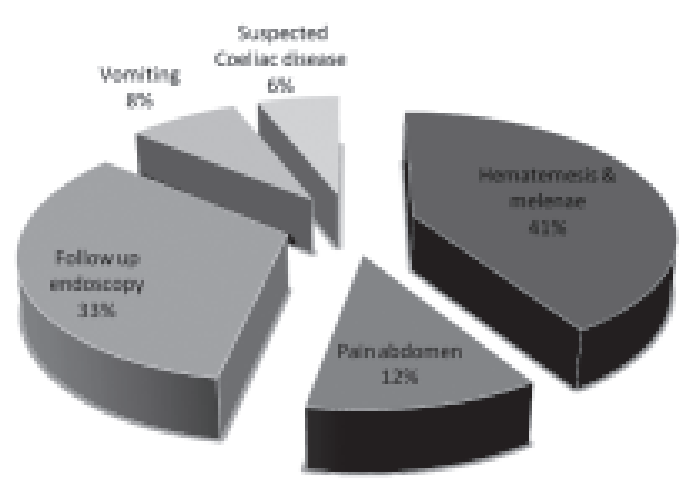

Fig.-1: Indications for UGI Endoscopy $(n=100)$

Table-II

Endoscopic findings of studied patients $(n=100)$

\begin{tabular}{lcc}
\hline Findings & No & Percentage (\%) \\
\hline Esophagial varices & 49 & $49 \%$ \\
Normal & 36 & $36 \%$ \\
Esophagitis & 6 & $6 \%$ \\
Gastritis & 4 & $4 \%$ \\
Gastroduodenal ulcer & 4 & $4 \%$ \\
Duodenal polyp & 1 & $1 \%$ \\
\hline
\end{tabular}

\section{Discussion}

Upper $\mathrm{Gl}$ endoscopy is one of the most specific, quick and cost effective diagnostic tool for a wide variety of 
gastrointestinal disorders in children, it was done especially under the circumstances when other investigations are not conclusive. In addition to its diagnostic use, upper GI endoscopy also has an established therapeutic role and various disorders like upper GI bleeding, Mallory Weiss tear, gastric erosions can be effectively treated by endoscopy. ${ }^{8-9}$ Therefore, despite changing indications over a period of time, the disorders requiring upper $\mathrm{Gl}$ endoscopy for diagnostic or therapeutic purposes in children have shown a rising trend. ${ }^{10}$ In the study hematemaesis and /or melenae (GI bleeding) was the most common $(41 \%)$ indication for the procedure. Upper GI bleeding was the third common (17.4\%) indication for upper GI endoscopy in another study by Khan, et al. ${ }^{11}$ This figure is much lower than present study. It may be due to clustering of patients in our centre, as it is the only tertiary centre where pediatric endoscopy is available. In literature from most of the developing countries, recurrent abdominal pain has been reported to be the commonest indication of upper $\mathrm{Gl}$ endoscopy. In various reports, this frequency of abdominal pain is reported to be ranging from $8 \%$ to $43 \% .^{12-14}$ In our study, the frequency of abdominal pain as an indication of upper $\mathrm{Gl}$ endoscopy was $12 \%$. So our results are comparable to other reports from developing countries. Similarly, almost one third of the children (36\%) who underwent upper GI endoscopy in our study had normal endoscopic findings. Thus, endoscopic diagnosis was established in $64 \%$ of patients in our centre. Esophageal varices was the most common endoscopic finding in the present study, seen in $49 \%$ of children. Recent report by Khan, et al. ${ }^{11}$ have shown esophageal varices in only $5 \%$ of paediatric upper $\mathrm{Gl}$ endoscopy. Our result is far away from this because of referral bias which has already been mentioned above. Regarding the other findings, gastroesophagitis and gastroduodenal ulcers were seen in few cases. Though reflux esophagitis is not very uncommon, gastritis and gastroduodenal ulcers (often associated with indiscriminate use of NSAIDS) are otherwise rare in paediatric age group. Though, the procedure is safe and can be performed even without sedation or anesthesia in adult patients, there is no specific guidelines for pediatric age group in this regard. Even in latest consensus guidelines developed by Canadian Association of Gastroenterology, the concerns have been raised regarding sedation/ anesthesia in children. ${ }^{15}$ Non-sedated procedure is cost effective and time saving, ${ }^{16}$ in our study about $2 /$
3 of the endoscopies were performed in non-sedated state. Approximately $60 \%$ of the upper GI related complications are secondary to sedatives/analgesic agents which can lead to cardiopulmonary compromise. ${ }^{17}$ No immediate post procedure complications were noted in our study. However, there is need to develop guidelines for sedation in children not only to save resources but also to prevent unnecessary exposure to sedatives.

\section{Conclusion}

Upper GI bleeding was the commonest indication, and esophageal varices was the most common finding of Paediatric upper GI endoscopy in this study. No significant premedication or procedure related complications were observed. Upper $\mathrm{Gl}$ endoscopy is thus may be a safe and useful diagnostic procedure in children .

\section{References}

1. El-Mouzan MI, Abdullah AM, Al-Sanie AM, Al Khalifa SI. Pattern of Gastro Esophageal Reflux in Children. Saudi Med J. 2001; 22: 419-22.

2. Sircus W. Milestones in the Evolution of Endoscopy: A Short History. J RColl Physicians Edinb. 2003; 33: 124-34.

3. Haight $M$ and Thomas DW. Pediatric Gastrointestinal Endoscopy. Gastroenterologist. 1995; 3: 181-86.

4. Papp JP. Endoscopic Experience in 100 Consecutive Cases with the Olympus GIG Endoscope. Am J Gastro. 1973; 60: 466-72.

5. Gleason WA, Tedesco FJ, Keating JP, Goldstein PD. Fiber Optic Gastrointestinal Endoscopy in Infants and Children. J Pediatr. 1974; 85: 810-13

6. Graham DY, Klish WJ, Ferry GD, Sabel JS. Value of Fiber Optic Gastrointestinal Endoscopy in Infants and Children. South Med J. 1978; 71: 558-60.

7. Ament ME, Berquist WE, Vargas J, Perisic V. Fiberoptic upper intestinal Endoscopy in infants and children. Pediatr Clin North Am. 1988; 35: 141-55.

8. Okello TR. Upper Gastrointestinal Endoscopic Findings in Adolescents at Lacor Hospital, Uganda. Afr Health Sci. 2006;6: 39-42.

9. Ginger MA. Gastroenterologic Endoscopy in Children: Past, Present and Future. Curr Opin Pediatr. 2001;13: 429-34. 
10. Murray JA, Vandyke C, Plevak MF, Dirisking RA, Zinsmeister RA, Melton LJ. Trends in the Identification and Clinical Features of Celiac Disease in a North American Community, 19502001. Clin Gastroenterol Hepatol. 2003;1: 1927.

11. Khan MR, Ahmed S, Ali SR, Maheshwari PK, Jamal MS. Spectrum of Upper GI Endoscopy in Pediatric Population at a Tertiary Care Centre in Pakistan. OJ Ped. 2014; 4:180-84.

12. Joshi MR, Sharma SK, and Baral MR. Upper GI Endoscopy in Children- in an Adult Suite. Kathmandu Univ Med J. 2005; 3:111-14.

13. Mudawi HM, Tahir MA, Suleiman SH, Eltaybe NH, Gamer NM, Abdullah FA. Paediatric Gastrointestinal Endoscopy: Experience in a Sudanese University Hospital. East Meditarr Health J. 2009;15: 1027-31.
14. Hafeez A, Ali S, Hassan M. An Audit of Pediatric Upper Gastrointestinal Endoscopies. J Coll Physicians Surg Pak. 2000;10:13-15.

15. Bishop PR, Nowicki MJ, May WL, Elkin D, Parker PH. Unsedated Upper Endoscopy in Children. Gastrointest Endosc. 2002;55: 624-30.

16. Armstrong D, Barkun A, Bridges R, Carters R, Degara C, Dube C. Canadian Association of Gastroenterology Consensus Guidelines on Safety and Quality Indicators in Endoscopy. Can J Gastroenterol. 2012; 26; 17-31.

17. Ben-Menachem T, Decker GA, Early DS, Evan J, Fanelli RD, Fisher DA. American Society for Gastrointestinal Endoscopy. Standards of Practice Committee. Adverse Events of Upper GI endoscopy. Gastrointest Endosc. 2012; 76:707-18. 